\title{
Lettre et critique, actes du colloque de Brest, 24-26 avril 2001, édités par Pierre-Jean Dufief,
}

\section{Laurence Richer}

\section{(2) OpenEdition}

1 Journals

\section{Édition électronique}

URL : http://journals.openedition.org/studifrancesi/36263

DOI : $10.4000 /$ studifrancesi.36263

ISSN : 2427-5856

Éditeur

Rosenberg \& Sellier

\section{Édition imprimée}

Date de publication : 1 juillet 2005

Pagination : 173

ISSN : 0039-2944

\section{Référence électronique}

Laurence Richer, «Lettre et critique, actes du colloque de Brest, 24-26 avril 2001, édités par Pierre-Jean Dufief, », Studi Francesi [En ligne], 145 (XLIX | I) | 2005, mis en ligne le 30 novembre 2015, consulté le 20 avril 2021. URL : http://journals.openedition.org/studifrancesi/36263 ; DOI : https://doi.org/ 10.4000/studifrancesi.36263

Ce document a été généré automatiquement le 20 avril 2021.

\section{(c) $(9)$}

Studi Francesi è distribuita con Licenza Creative Commons Attribuzione - Non commerciale - Non opere derivate 4.0 Internazionale. 


\title{
Lettre et critique, actes du colloque de Brest, 24-26 avril 2001, édités par Pierre-Jean Dufief,
}

\author{
Laurence Richer
}

\section{RÉFÉRENCE}

AV. vv., Lettre et critique, actes du colloque de Brest, 24-26 avril 2001, édités par PierreJean DUFIEF, Publications du Centre d'étude des correspondances et journaux intimes des XIX ${ }^{e}$ et XX $\mathrm{XX}^{\mathrm{e}}$ siècles, CNRS-UMR 6563, Université de Bretagne occidentale, 2003, pp. 416.

1 Pierre-Jean DUfIEF situe d'emblée son propos par rapport à la grande mutation de la critique, qui, au XIX ${ }^{e}$ siècle, devient un champ littéraire autonome, souvent lié à la presse. Face à cette professionnalisation se fait ressentir le besoin d'une critique plus intime, souvent novatrice, formulée dans la correspondance. Les contributions réunies en examinent les variations à travers les correspondances des $\mathrm{XIX}^{\mathrm{e}}$ et $\mathrm{XX}^{\mathrm{e}}$ siècles, conformément à l'objet de l'UMR 6563, maîtresse d'ouvrage du projet. La présente recension rend compte des communications portant, par la chronologie ou l'esprit, sur la première moitié du siècle.

2 Sophie maRchal (pp. 11-41) suit chez Vigny une évolution. Ses lettres lui permettent d'abord de développer une critique romantique militante, la «camaraderie critique». Mais il y affirme aussi sa poétique personnelle. Louis LE GUILLOU (pp. 93-98) montre comment Michelet peut assimiler deux genres, la lettre et le cours. Dans ses lettres aux critiques, Sainte-Beuve en particulier, il explique son œuvre et rappelle les spécificités disciplinaires de l'histoire, dont, en cette époque, les critiques littéraires rendent encore compte. André GUYAUX (pp. 43-55) parle des lettres de Baudelaire à Armand Fraisse: Baudelaire a peu d'occasions d'engager le dialogue avec des critiques favorables à son œuvre; Armand Fraisse lui donne l'une de ces occasions, ce qui fait tout l'intérêt 
de cet échange. Le titre même de l'article de Catherine tномаs (pp. 79-92) doit être cité: «Lectures critiques des mémoires et des correspondances du XVIII ${ }^{e}$ siècle au cours du XIX siècle», car il témoigne d'une intéressante ouverture du champ du colloque, les deux termes lettre et critique entrant dans une relation nouvelle par le biais d'une étude de réception. Pierre Dufief, au-delà des Goncourt, qui échappent au champ chronologique ici traité, propose aussi une réflexion théorique dense qui tend à constituer la critique épistolaire en sous-genre.

Réflexion sur la critique, ce livre est aussi un modèle de critique. Le recueil d'articles y remplit parfaitement ses deux buts. La diversité d'approches met en valeur la liberté d'un sous-genre qui «invente constamment ses codes», pour reprendre l'expression de Pierre Dufief. Mais il constitue aussi une réflexion essentielle autant que synthétique sur la critique épistolaire, dans une saisie diachronique toujours significative. 